\title{
Sustainable development indicators: CompiteMAS, a new platform for small and medium enterprises
}

\author{
R. Chamy, E. Vivanco \& I. Sánchez \\ Núcleo de Biotecnología de Curauma, \\ Pontifical Catholic University of Valparaiso, Chile
}

\begin{abstract}
Pontificia Universidad Católica de Valparaíso has been developing a National Project named "CompiteMAS". One of the goals of that project is based on creating a set of sustainability indicators for Small and Medium Enterprises (SMEs) in Chile. Today this platform is being implemented in other countries in the region. At least 30 general indicators for social, environmental and production aspects in companies were created, as well as 30 more indicators regarding specific sustainability features in specific sectors were added. A table of contents has been developed for each indicator, in which formula, periodicity, goals and description are described. Finally, individual data of each company are collected and included in the CompiteMAS platform. That website transforms social, environmental and production data into indicators to analyse the sustainability work for a specific period of time. After that, to establish a benchmark by each production sector, the calculated indicators are chosen by aspect to create a ranking. That matrix gives information to the organizations about their good results at, for example, energy efficiency or social responsibility actions, compared with the remaining companies for the same period and production sector. Thanks to that project, smaller Chilean companies can report their indicators using sustainability reporting as a strategy to enter into new markets, which demands transparency and the companies' information.

Keywords: small and medium enterprises, sustainability indicators, platform, benchmarking.
\end{abstract}




\section{Introduction}

On one hand, small and medium companies in developing countries have presented extended environmental barriers on international markets, due to a low capacity to identify market requirements and achieve their expectations. Besides, smaller companies present a lack of standardized information and Monitoring Reporting and Verification Methodologies (MRV).

On the other hand, several countries do not have enough statistics on indicators that give them information about SME sustainability performance. Because of that situation, free access to information for SMEs, National environmental indicators inventory, development of methodological tools or strategy recommendations are some of solutions that CompiteMAS Project offers. That Chilean Project has been developing since 2012 to increase the competitiveness of SMEs in Chile through a digital platform that provides tools and strategies to guide companies to increase their transparency, sustainability and efficiency. To do so, Global Reporting Initiative, ISO 26000, ISO 14001, World Resources Institute recommendations and some other regulations like Standard UNE EN 66175:2003 were analyzed to find the way to allow smaller companies to measure their work as sustainable companies. In order to adapt those standards, some main criteria must be met, such as being measurable, relevant, and easy to measure, timely and specific [1-5].

In addition, that project allows SMEs to calculate their carbon footprint and then identify which National Actions for a specific sector could be a National Appropriate Mitigation Action (NAMA) for the country. For example, that platform supports the Monitoring Reporting and Verification Protocol for a Chilean NAMA based on Clean Agreement Production, through registration of indicators, which are used to calculate the carbon footprint mitigation [6].

CompiteMAS Platform has been also implemented in Peru since January 2015, thanks to Pathways to Prosperity Innovation Challenge 2014, financed by the US Department of State. "CompiteMAS" achieved an award in the Facilitating Category, receiving financial and technical support to scale up this initiative in Peru.

\section{Goals}

CompiteMAS Project is developed to achieve the following main goals:

- Increase the competitiveness of small and medium companies through monitoring, registration and verification of sustainability indicators

- Improvement information access to Better Available Technologies

- Reduce management system implementation costs

\section{Methodology}

In order to achieve those goals, the Project is based on a methodology that is represented in the following steps: 
1. Analysis of the sustainability sectorial gap. To do that, the baseline determination is necessary for SMEs that are organized by sectorial associations. Then, economic, social and environmental characteristics are analysed for each specific sector. Information about international market requirements, sectorial standards and other barriers are systematized through meetings and interviews with the sectors. In that point, also it is important to understand the technological access of the companies and how many platforms and other systems they use to monitor the sustainability of their work.

2. Sustainability indicators definition. Once gaps have been identified, sectorial associations and CompiteMAS workers develop a set of indicators based on economic, social and environmental quantitative values. Those indicators have the following characteristics:

a. They are clear to people with a basic knowledge of the issue, they are specific and well defined for SMEs with low capacities

b. They are able to be measured in a quantitative manner

c. They are realistic, practical and achievable

d. They are relevant and contribute to make decisions

e. They are timely.

3. Then, a table of contents for each indicator is developed, in which the formula, periodicity, goal and description are included.

4. CompiteMAS Platform. This platform allows creating any type of form with specific validations. These forms are used for different types of enterprises considering their purpose. For example, enterprises from the dairy industry are organized in one group and complete a form created specifically for them. Once the enterprises are classified and have filled out the form with specific data, the system generates different types of indicators, applying mathematical formulas. The indicators are then classified as environmental, economic or social indicators. After this process, the system generates rankings, comparing enterprises within the same group. Another function of the system is the possibility to upload training documents. These documents aim to improve the enterprises' indicators. Afterwards, the system evaluates the learning outcome of the documents and provides the users with the results. The system classifies the data according to time periods of one year. Using this classification, the system then generates information according to the evolution of the enterprise, considering the data from the different time periods the enterprise has been using the system. This will allow the enterprises compare their own data from different periods of time. The system generates a document with the results of each of enterprises' periods. The tools used for the development of this system are based on the Symphony 1.4 framework. The system uses Amazon Web Services.

5. Increase of the capacities: Along the companies' monitoring of the sustainability of their process, they can develop plans and programs, which allow implementing a defined sustainability policy inside the company. CompiteMAS platform helps SMEs to follow their performance and obtain an extended knowledge about their hot spots along the process. 
6. CompiteMAS Platform also helps establishing indicators for Registration Monitoring Verification of NAMAs. To do so, CompiteMAS calculates parameters that measure the carbon footprint mitigation thanks to actions implemented in SMEs such as energy efficiency or solid waste treatment.

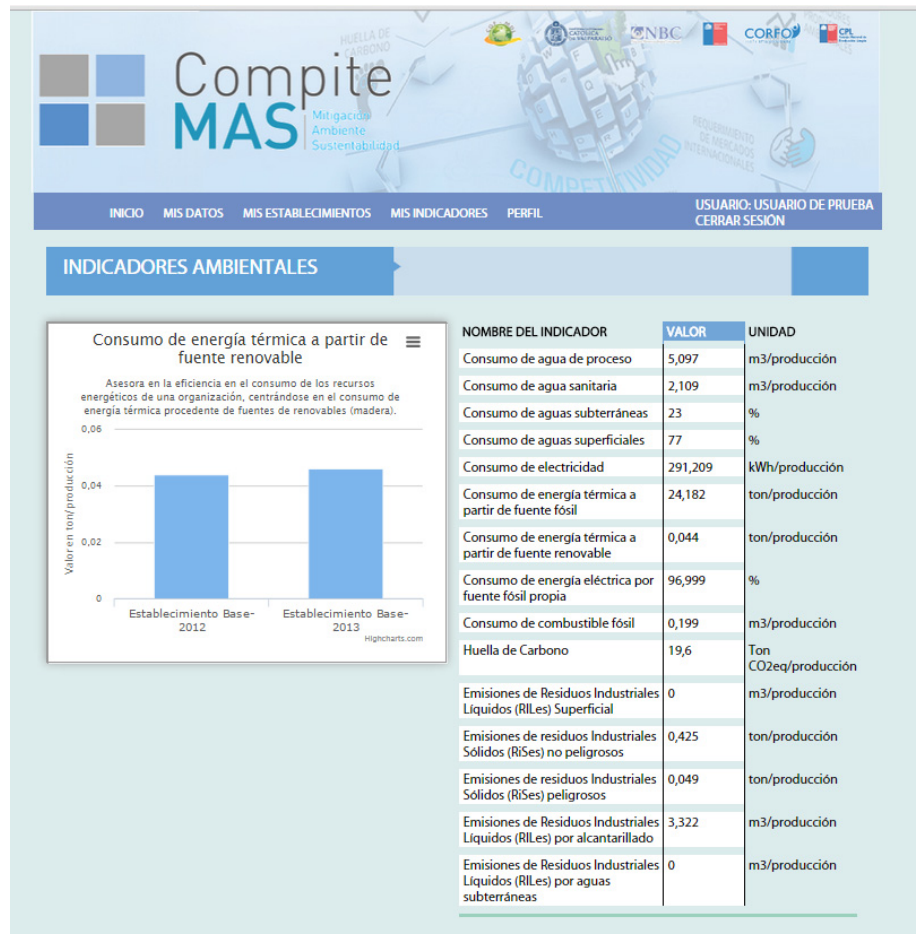

Figure 1: Evolution indicator registration through CompiteMas Platform.

\section{Results}

Each indicator calculated by CompiteMAS was analysed to measure their contribution to some environmental global impact, like Climate Change. Agriculture, Manufacturing and Tourism Companies contributions are represented in the Figures 2, 3 and 4.

On the other hand, thanks to CompiteMAS platform, a cleaner production has been achieved in many SMEs. Mitigation climate change actions can be identified through indicators which have been registered for each company in CompiteMAS Platform.

From 2012 to 2013, at least 7 SMEs registered in CompiteMAS, of the food industry in Chile implemented an adequate solid waste management, archiving a rate of $10 \%$ of recycle for the total waste generated in those companies Moreover, the same companies implemented energy efficiency measures in their process. So, $389,228.72 \mathrm{tCO}_{2}$ eq was been reduced in the same period of time. 


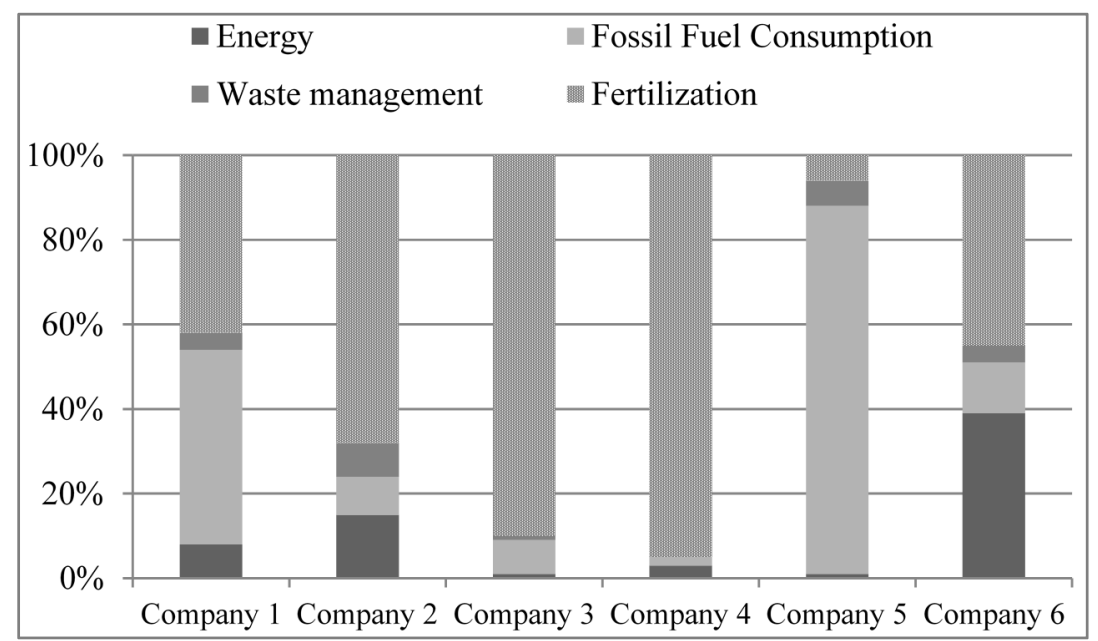

Figure 2: $\quad$ Impact model calculated to agriculture example companies.

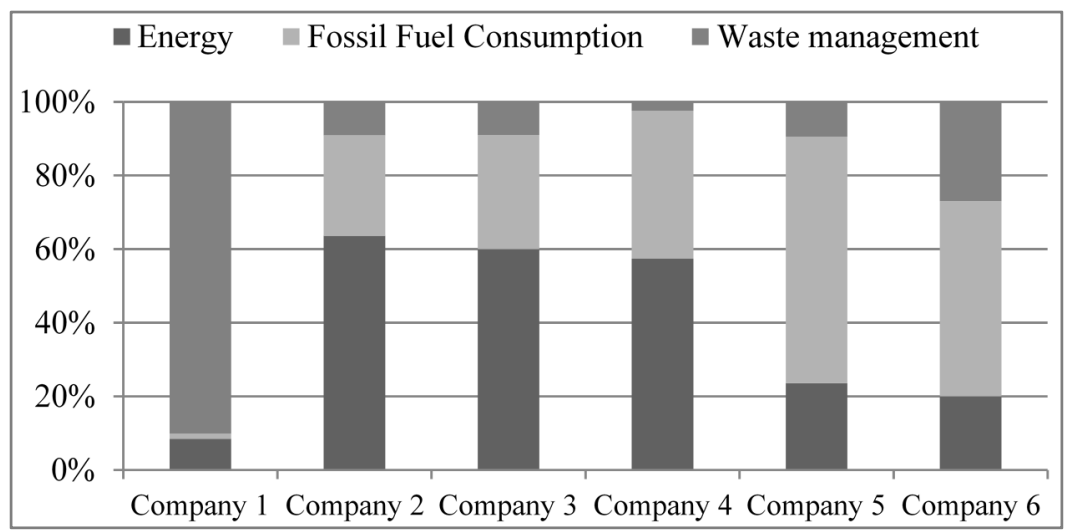

Figure 3: $\quad$ Impact model calculated to manufacture example companies.

From 2013 to 2014, three companies of fishing sector started to use CompiteMAS and implemented clean production actions. Improvement of solid waste management, reduction of waste water effluent and energy efficiency measures was some of those actions. Thanks to that, CompiteMAS registered a total reduction of $144 \mathrm{tCO}_{2} \mathrm{eq}$ for that period of time. Another two companies, bigger than medium company size, include a manage plan for the $80 \%$ of biosolids generated, so $494,725 \mathrm{tCO}_{2} \mathrm{eq}$ was reduced. Finally it is important to notice that mitigation results depend on the productivity of each specific sector so carbon footprint per production must be considered. In the following chart, distribution of mitigation potential by several companies, which belong to food industry, is represented. 


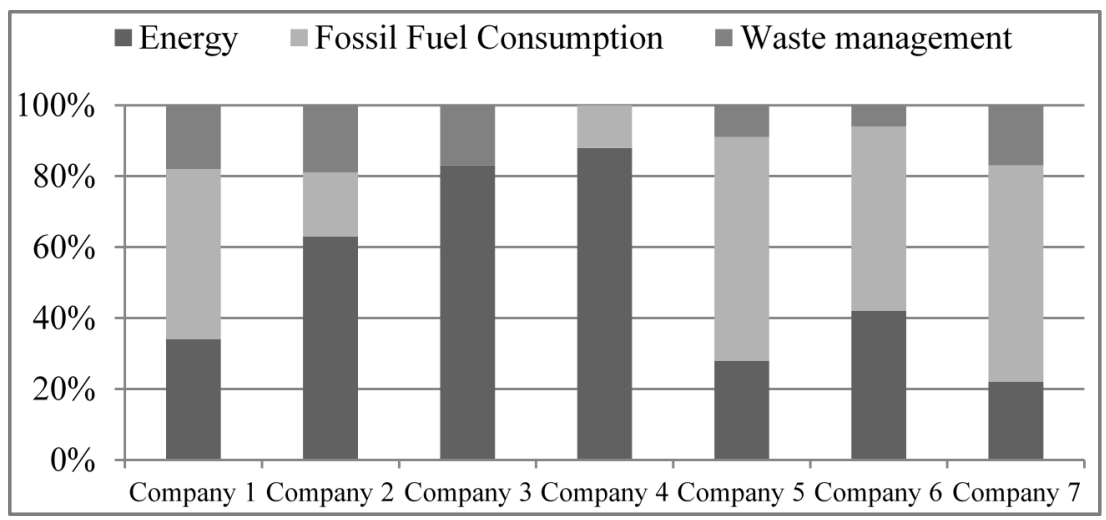

Figure 4: Impact model calculated to truisms example companies.
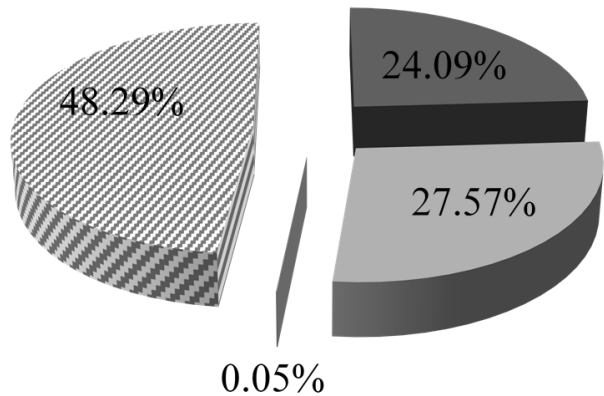

Juice

Chocolate

Sweet

Sausages and meat

Figure 5:

Mitigation contribution by food industry.

Also, thanks to CompiteMAS, at least 100 SMEs along Chile have been trained not only for Carbon FootPrint calculation but also in sustainability indicators monitoring.

\section{Conclusions}

Thanks to the CompiteMAS Platform implementation, at least 100 SMEs in Chile have just measured their sustainability indicators. Specifically, 8 manufacturing companies have registered their Greenhouse Gases Emissions Mitigation through that platform, verifying a total reduction of $389,000 \mathrm{tCO}_{2} \mathrm{e}$ according to the baseline.

CompiteMAS is nowadays expanding to other countries, looking for solutions to smaller companies that need to face the green requirements of international markets. 


\section{References}

[1] Acción Empresarial, Reporte Social Empresarial: Guía práctica para el reporte social y medioambiental de las empresas, 2002

[2] Asociación Española de Normalización y Certificación, AENOR. UNE 66175: Sistemas de gestión de la calidad: Guía para la implantación de sistemas de indicadores, 2003

[3] Global Reporting Initiative, Guía para la Elaboración de Memorias de Sostenibilidad sobre el desempeño económico, ambiental y social de la empresa, 2002

[4] Rayén Quiroga, M. Indicadores de sostenibilidad ambiental y de desarrollo sostenible: estado del arte y perspectivas. División de Medio Ambiente y Asentamientos Humanos, CEPAL, 2001.

[5] Servicios Avanzados del Consorcio de la Zona Franca de Vigo. Indicadores de competitividad de la empresa gallega, Ardán Galicia, 2011

[6] Oficina de Cambio Climático, Ministerio del Medio Ambiente de Chile, Primer Informe Bienal de Actualización de Chile, 2014 